\title{
Effects of Alzheimer Disease on Patients and Their Family
}

\author{
Barbara J. Grabher, BS, CNMT, RT(N) \\ Grabher Consulting and Specialty Services, Abingdon, Maryland, and Life Molecular Imaging, Inc., Boston, Massachusetts
}

CE credit: For CE credit, you can access the test for this article, as well as additional JNMT CE tests, online at https://www.snmmilearningcenter.org. Complete the test online no later than December 2021. Your online test will be scored immediately. You may make 3 attempts to pass the test and must answer $80 \%$ of the questions correctly to receive $1.0 \mathrm{CEH}$ (Continuing Education Hour) credit. SNMMI members will have their CEH credit added to their VOICE transcript automatically; nonmembers will be able to print out a CE certificate upon successfully completing the test. The online test is free to SNMMI members; nonmembers must pay $\$ 15.00$ by credit card when logging onto the website to take the test.

The diagnosis of Alzheimer disease (AD) affects not only the patient but the entire family and their supporting caregivers. Understanding the stressors that affect these individuals enables us to provide the support and care they need to remain happy and healthy despite living with the diagnosis of $A D$. This continuing education article examines the epidemic of $A D$ in the United States today and its emotional, psychologic, and financial effects. It discusses ways that caregivers can reduce their own stress as they struggle to balance family responsibilities with caring for their loved one with AD. Although there is no cure for $A D$, research suggests there are ways to reduce the risk of developing $A D$; these will be explored here as well.

Key Words: Alzheimer disease; Alzheimer disease statistics; effects of Alzheimer disease on patient; Alzheimer disease caregivers

J Nucl Med Technol 2018; 46:335-340

DOI: 10.2967/jnmt.118.218057

\section{A}

lzheimer disease (AD) was discovered on November 25, 1901, when Dr. Alois Alzheimer examined and observed a patient named Auguste Deter at the Frankfurt Asylum for the Insane and Epileptic. The 46-y-old patient had strange behavioral symptoms, including a loss of shortterm memory. In April 1906, at the age of 51, Mrs. Deter died. Alzheimer had obtained her patient records, and her brain was brought to him in Munich. Along with 2 Italian physicians, Alzheimer used cell-staining techniques to identify amyloid plaques and neurofibrillary tangles within the cortical gray matter of the brain. On November 3, 1906, he gave the presentation that first linked these pathologic findings with the clinical symptoms of presenile dementia (1).

Today, over 110 y later, $\mathrm{AD}$ is a devastating disease that affects more than 46.8 million people worldwide. This

\footnotetext{
Received Jul. 18, 2018; revision accepted Aug. 17, 2018.

For correspondence or reprints contact: Barbara J. Grabher CNMT, RT(N), Grabher Consulting and Specialty Services, 3113 Pouska Rd., Abingdon, MD 21009.

E-mail: barbara.grabher@gmail.com

Published online Aug. 23, 2018.

COPYRIGHT (c) 2018 by the Society of Nuclear Medicine and Molecular Imaging.
}

number is expected to double every $20 \mathrm{y}$, reaching 75 million in 2030 and 131.5 million in 2050 (2). AD currently affects over 5.7 million people in the United States and is expected to grow at a rate similar to the worldwide statistics mentioned above, nearly tripling by 2050 to a projected 14 million cases in people 65 y old or older (3). Currently, 5.5 million people are at least $65 \mathrm{y}$ old -3.3 million women and 2 million men, and the prevalence of $\mathrm{AD}$ in people $65 \mathrm{y}$ old or older is 1 in 10 (3). Among AD patients, $81 \%$ are $75 \mathrm{y}$ old or older, $15 \%$ are $65-74 \mathrm{y}$ old, and $4 \%$ are younger than $65 \mathrm{y}$ (4). Approximately 200,000 individuals with AD are under the age of $65 \mathrm{y}$ and have what is called younger-onset or early-onset $\mathrm{AD}$ (5). The statistics related to $\mathrm{AD}$ and its effect on the patient, family, and entire health-care system are staggering (5): $\mathrm{AD}$ is the sixth leading cause of death in the United States; 1 in 3 seniors die with AD, every 65 seconds someone in the United States develops AD, and AD kills more people than do breast cancer and prostate cancer combined. In 2018, more than 16.1 million caregivers will provide an estimated 18.4 billion hours of unpaid care, yet $\mathrm{AD}$ costs caregivers more than just their time. Some family members spend more than $\$ 10,000$ a year caring for someone with AD. For some families, caring for an $\mathrm{AD}$ patient means missing a vacation, but for others it may mean going hungry. In 2018, AD and other dementias will cost the nation $\$ 277$ billion.

Because our population is living longer-sometimes referred to as the Silver Tsunami (6) - the number of people with $\mathrm{AD}$ will continue to grow, putting increasingly more strain on family and caregivers emotionally and on the entire health-care system financially. New strategies, support groups, and even AD communities need to be created for patients and caregivers. The impact of the diagnosis on caregivers is multifaceted, ranging from economic concerns to concerns about having to alter their lifestyle to care for the patient. Being aware of their concerns, needs, and feelings allows the community to help them cope.

\section{RISK FACTORS FOR DEVELOPING THE DISEASE}

There are both controllable and uncontrollable risk factors for $\mathrm{AD}$, with age being the leading known uncontrollable one (7). Most people are diagnosed at the age of $65 \mathrm{y}$ or older (3). 
Another uncontrollable risk factor is family history. Individuals who have a first-degree relative (parent or sibling) with the disease are more likely to develop it than those who do not, and those who have more than one first-degree relative with the disease are at even higher risk (3). Genetics is also an uncontrollable risk factor, as there are 3 genes linked to early-onset $\mathrm{AD}$ and a fourth gene, apolipoprotein $\mathrm{E}$, linked to late-onset $\mathrm{AD}$ (7). A final uncontrollable risk factor is sex, with more women than men having $\mathrm{AD}$ and other dementias. Almost two thirds of Americans with AD are women. Also, among people $71 \mathrm{y}$ old or older, $16 \%$ of women have $\mathrm{AD}$ or other dementias, compared with $11 \%$ of men (3). There are several possible reasons why more women than men have $\mathrm{AD}$ and other dementias, the biggest being that women live longer than men, on average, and that older age is the greatest risk factor for $\mathrm{AD}(3)$.

Controllable risk factors for $\mathrm{AD}$ include high cholesterol levels, high blood pressure, lack of regular exercise, and lack of intellectually stimulating activities (7).

\section{BENEFITS TO KNOWING A DIAGNOSIS}

Knowledge of the diagnosis has value to both the patient and the family. According to a survey in 2011 (8), 84\% of respondents would want to be told if their loved one had AD, $98 \%$ would want a family member exhibiting confusion and memory loss to see a doctor, and $89 \%$ would, themselves, want to know if they had AD. Cognitive impairment needs to be diagnosed as early as possible in the disease process. The value of knowing, especially in the early stages of the disease, is that the patient and family can plan for the future. The patient has more opportunities to be involved in decisions about current and future living arrangements, personal care, and financial and legal matters while still having the ability and the cognition to make such decisions (9). Early diagnosis also allows patients to receive the maximum benefit from treatment, in addition to being able to remain independent longer and have a better chance of participating in clinical trials, which can help stabilize, slow, or even reverse the amyloid plaque buildup in the cortical gray matter of the brain (10). An early and documented diagnosis leads to better outcomes for individuals with $\mathrm{AD}$ and their caregivers (10).

According to one author (11), "Dealing with legal and financial issues is a critical first step after a diagnosis of AD. Prompt action, before the patient becomes incapacitated, will help the family understand the patient's wishes." Choosing a lawyer, accountant, and financial planner can be helpful in addressing the many legal and financial issues to ensure the patient is cared for and protected. For example, these professionals can assist with setting up a trust or a living trust, planning how to finance long-term care, writing a will or a living will, allocating a guardian or a health-care proxy, setting up a medical or durable power of attorney, and planning the estate (11).

\section{PAID AND UNPAID COSTS OF CARE}

Payments by Medicare and Medicaid for health care, long-term care, and hospice for people with $\mathrm{AD}$ and other dementias were $\$ 150$ billion in $2014, \$ 236$ billion in 2016 , and are estimated to be $\$ 277$ billion in $2018(3,4,12)$. Although these agencies and private insurers do cover some of these costs, Medicare does not cover the entire cost of chronic care. If an $\mathrm{AD}$ patient requires chronic care, the maximum coverage by Medicare is just $150 \mathrm{~d}$ and involves deductibles and copayment for which the patient is responsible (12). In 2017, Medicare beneficiaries aged 65 or older with $\mathrm{AD}$ and other dementias paid $\$ 10,589$ out of pocket, on average, for health-care and long-term care services not covered by other sources (3). AD patients also experience more hospitalizations than other people the same age, also increasing the financial burden to patients and family (4). People with AD or other dementias comprised $29.9 \%$ of individuals in adult day care in $2014,39.6 \%$ of those living in residential care communities in $2014,31.4 \%$ of those using the services of home health agencies in $2013,44.7 \%$ of those in hospice in 2013, and 50.4\% of those living in nursing homes in 2014 (13), all of which cost the patient and family a significant amount of money. A 2013 article claimed that $\mathrm{AD}$ is one of the costliest chronic diseases to society (14), and in 2014, the director of the Mayo Clinic Alzheimer's Disease Research Center stated that "If we don't get on top of [AD], it will bankrupt the health-care system" (15).

A 2016 report found that those who provide care are $28 \%$ more likely than those who do not to struggle with having enough money for proper meals (4). Another finding was that many family members and friends of people with $\mathrm{AD}$ or other dementias make great sacrifices to help provide care, such as spending money from their savings and retirement accounts, thus jeopardizing their own financial security. Startlingly, the report also revealed that many caregivers cut back on basic necessities such as food and medical care for themselves and their families and did not know, or had misconceptions about, which expenses Medicare and Medicaid cover, leaving them unprepared to handle the tremendous costs associated with the disease. Another finding was that caregivers spent an average of $\$ 5,155$ of their own money per year to take care of their relative or friend with $\mathrm{AD}$ or another dementia. The annual out-of-pocket costs ranged from less than $\$ 1,000$ to more than $\$ 100,000$, and it was the spouse or partner who incurred the highest expense - an average of over $\$ 12,000$ per year. Adult children spent an average of about $\$ 4,800$ per year, with some (16\%) spending $\$ 10,000$ or more. The most common expenses were for groceries, followed by travel, medical supplies (e.g., adult diapers), medications, nonmedical in-home care, and in-home health care (4).

An underlying financial burden relating to the care of $\mathrm{AD}$ patients is the hours of unpaid care and the economic value of caregiving. One report (12) found that in 2013, the 15.5 
TABLE 1

Hours of Unpaid Care and Its Economic Value $(3,4,12)$

\begin{tabular}{lccc}
\hline \multicolumn{1}{c}{ Parameter } & 2013 & 2015 & 2016 \\
\hline Number of family and other unpaid caregivers & 15.5 million & 15.9 million & 15.9 million \\
Hours of unpaid care & 17.7 billion & 18.1 billion & 18.2 billion \\
Hours of care per caregiver per week & $21.9 \mathrm{~h}$ & $21.9 \mathrm{~h}$ & $21.9 \mathrm{~h}$ \\
Hours of care per caregiver per year & $1,139 \mathrm{~h}$ & $1,139 \mathrm{~h}$ \\
Hourly rate & $\$ 12.45$ & $1,139 \mathrm{~h}$ & $\$ 12.65$ \\
Total cost & $\$ 220.3$ billion & $\$ 221.3$ billion & $\$ 230$ billion \\
\hline
\end{tabular}

million family members and other unpaid caregivers of people with $\mathrm{AD}$ or other dementias provided an estimated 17.7 billion hours of care. This number represents an average of $21.9 \mathrm{~h}$ per caregiver per week, or $1,139 \mathrm{~h}$ per caregiver per year. With this care valued at $\$ 12.45$ per hour, the estimated value of this unpaid care was $\$ 220.3$ billion (12). In 2015, 15.9 million unpaid caregivers provided an estimated 18.1 billion hours of care, averaging $21.9 \mathrm{~h}$ per caregiver per week, or $1,139 \mathrm{~h}$ per caregiver per year. At $\$ 12.25$ per hour, the estimated value of this unpaid care was $\$ 221.3$ billion. Thus, from 2013 to 2015, the cost of unpaid care increased by $\$ 10$ billion. In 2016, 15.9 million unpaid caregivers provided an estimated 18.2 billion hours of care valued at $\$ 230$ billion. In a newly released 2018 report, over 16 million unpaid caregivers provided an estimated 18.4 billion hours of care, which at $\$ 12.61$ per hour (a $2.9 \%$ increase over the 2015 hourly rate) is valued at \$232 billion, an increase of almost 5\% from 2016 to 2018 and a total increase of over $\$ 12$ billion in 5 y $(3,4,12)$. These numbers are staggering and have had a big impact on caregivers, their families, and the economy, and unfortunately the numbers continue to grow. Table 1 summarizes these data for 2013, 2015, and 2016.

\section{SOURCES OF STRESS TO FAMILY CAREGIVERS}

\section{Demographic Stress}

Figure 1 illustrates caregiver demographics (4). A 2014 report indicated that because of demographic changes in the U.S. population (i.e., parents of dependent minors are older than in the past, and the U.S. population is aging), we now have something called the sandwich-generation caregiver, or a middle-aged person who simultaneously cares for dependent minor children and aging parents (12). The report found that $30 \%$ of $\mathrm{AD}$ and dementia caregivers had children under 18 y old living with them and that $8 \%-13 \%$ of households in the United States had sandwich-generation caregivers. Such caregivers experience many challenges, such as limited time, energy, and financial resources, when balancing the care of both aging parents and dependent children. Because of these unique challenges, such caregivers may experience increased anxiety and depression and a decreased quality of life (12).

\section{Work-Related Stress}

Family caregivers also experience work-related stress, such as the need to adjust their work schedule to accommodate caring for their loved one. Reports show that $57 \%$ of caregivers had to go in to work late, leave early, or take time off; that $16 \%$ had to take a leave of absence; and that $18 \%$ had to change from full-time to part-time work, a $5 \%$ increase in 2017 over 2016 data $(3,4,12)$. Other work-related issues caregivers experienced were having to take a less demanding job (13\%), having to give up working entirely (9\%), receiving a warning about performance or attendance $(7 \%)$, and having to retire early $(6 \%)(3,8)$.

\section{Time-Related Stress}

Another stressful issue for families and caregivers is finding enough time to visit a loved one who is in a skilled care facility. If the loved one is cared for at home, the issue may be finding substitute caregivers when primary caregivers have other demands on their time. Issues may also arise with balancing the time needed to care for the patient with the time needed to care for self or other family members (12). According to one report (12), almost $23 \%$ of all caregivers are "on-duty" caregivers spending $24 \mathrm{~h}$ a day, $7 \mathrm{~d}$ a week, caring for the loved one. Interestingly, 59\% of those who were not on-duty caregivers felt as if they were. The report also stated that women are 2.5 times more likely than men to provide on-duty care in the late stage of disease.

Caregiver intervention is an important area where more support is needed. If the health and well-being of caregivers are neglected, those they care for will suffer as well. The

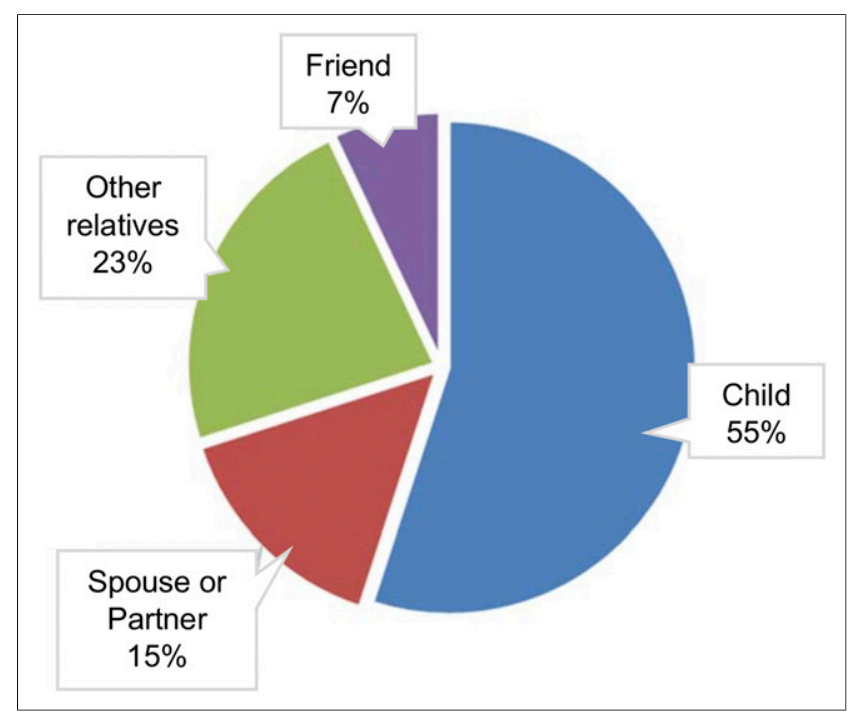

FIGURE 1. Caregiver demographics (8). 
desired outcome of caregiver intervention is successful management of stress and depression, which in turn delays the need to admit the AD patient to a nursing home (4). Some examples of intervention include counseling, support groups, case management support, and respite care (4), all of which can help caregivers be their best for the patient.

\section{Physical and Emotional Stress}

Reports from 2014 and $2018(3,4,12)$ cite both physical and emotional stress as being other burdens placed on families (Fig. 2); $47 \%$ of women and $24 \%$ of men considered their caregiving role to be physically stressful, and $62 \%$ of women and $52 \%$ of men considered their caregiving role to be emotionally stressful. Adding to the stress is that $51 \%$ of caregivers have no medical experience, creating difficulty with making decisions or knowing what to do next.

In a recent survey (Barbara J. Grabher, unpublished data, May 2017), the top 5 stressors for caregivers were found to be financial strain, fear that their loved one will get lost, effects on family vacations, caregiver stress of balancing all their family responsibilities with the responsibilities of taking care of their loved one, and reduced time with their family.

Three of the biggest issues family members face are a lack of privacy, sleep deprivation, and the lone-soldier syndromea sense that they have to bear the full burden of taking care of their loved one. A fourth issue is not anticipating what is coming next for their loved one, and a fifth is trying to manage the overwhelming task of taking care of their loved one (16). Incontinence, heavy lifting, and wandering behaviors in someone with $\mathrm{AD}$ are usually the most stressful issues; both urinary incontinence and fecal incontinence are among the leading causes of nursing-home placement (16).

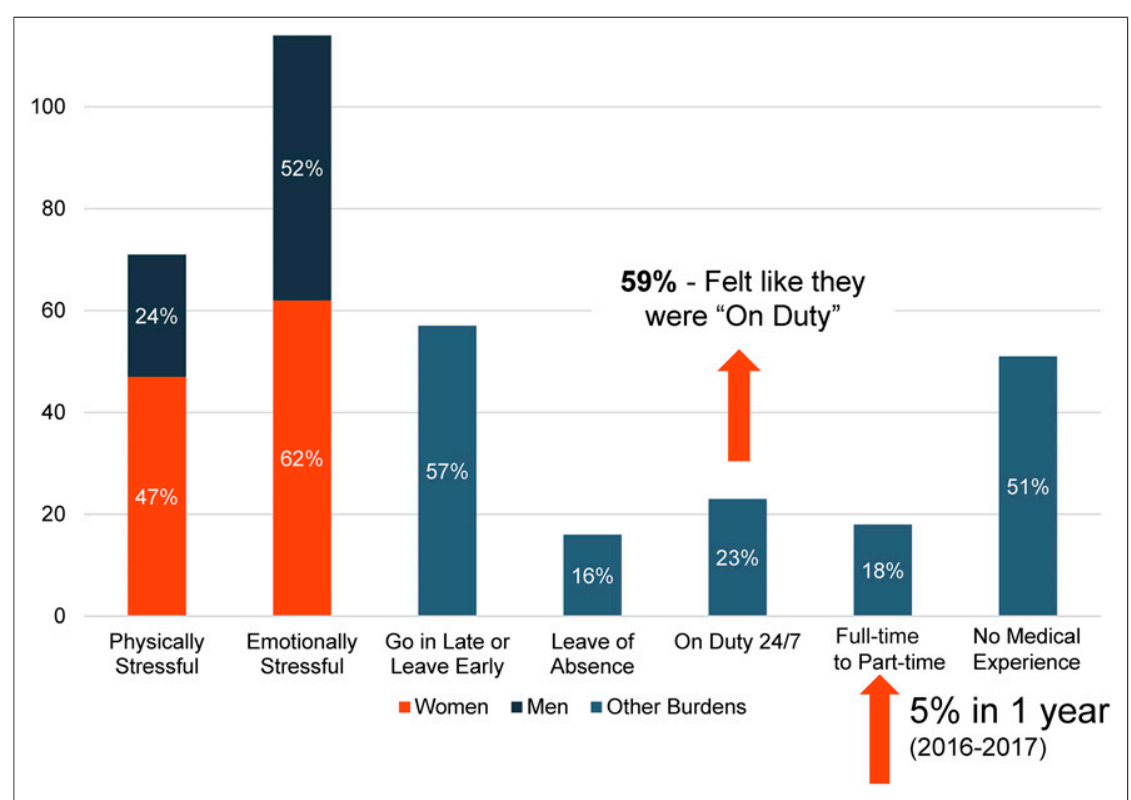

FIGURE 2. Physical and emotional burdens of $A D$ caregivers and family members $(3,4,12)$.
Once a patient is diagnosed with $\mathrm{AD}$, they too have stress related to their new diagnosis. The most common reasons patients give for increased stress are fears about forgetting their loved ones, becoming a burden to their family, losing their independence, and not being able to take care of themselves (12). In the early stages of disease, finances are the greatest cause of stress to patients, who may wonder whether they will have enough money to pay for their care.

Caring for AD patients creates emotional stress regardless of whether the care takes place at home or in a facility. Data from 2014 indicated that $76 \%$ of family caregivers for people with $\mathrm{AD}$ or other dementias agree-either somewhat or strongly - that it is neither right nor wrong for a family to decide to admit a family member to a nursing home. Yet many such caregivers feel guilt and emotional upheaval and have difficulty adapting to the admission (e.g., they have mixed emotions relating to what to do; their brain is telling them to place their loved one in an Alzheimer facility but their heart does not want to put their loved one in a nursing home facility) (12).

Family members of AD patients can experience many other types of feelings, including sadness, discouragement, aloneness, anger, and hope, as well as fatigue and depression (17). Different people handle stress and emotions differently, with some being able to express how they feel whereas others cannot. Emotions about the loved one with $\mathrm{AD}$ may be mixed. A family member may feel both love and dislike for the person at the same time or may want to care for the person at home while simultaneously wanting to hand over care to a facility. Embarrassment about how the patient behaves in public may also be a concern; however, this feeling might fade if the experience is shared with other family members, who can then share similar experiences of their own (17). Support groups are helpful in such situations by decreasing the feeling of being alone.

Two feelings that many family members have are helplessness and guilt. The feeling of helplessness may stem from having to take the loved one to multiple physicians before finally getting an accurate diagnosis of the cognitive impairment (17). Feelings of guilt may arise from many sources: family members may regret being impatient with the patient, losing their temper, or spending time with friends instead of with the patient. Other forms of guilt arise from wishing they did not have the responsibility of caring for their loved one, from considering placement in a facility, or from having to limit the patient's independence regarding driving, living alone, or finances (17). 


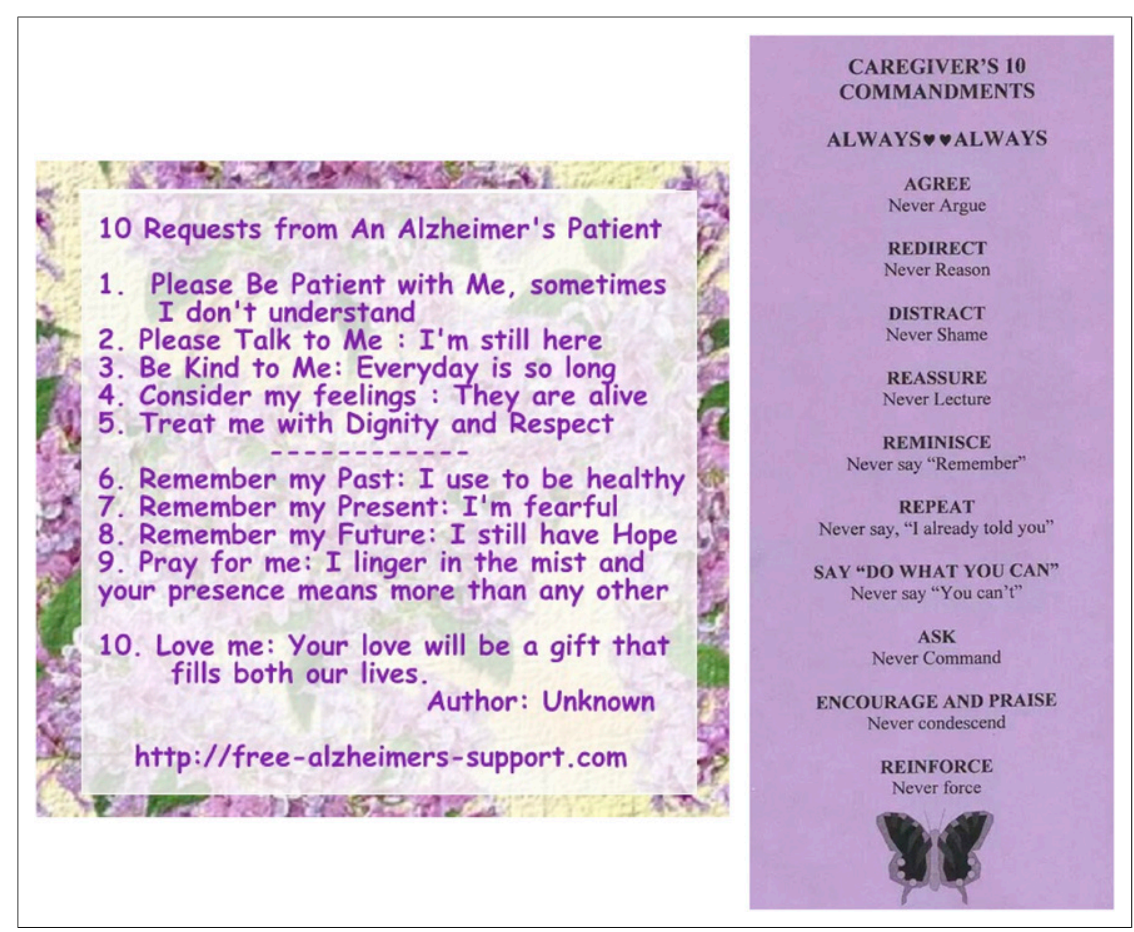

FIGURE 3. 10 Requests from an Alzheimer's Patient (20) and Caregiver's 10 Commandments (21).

\section{ALTERNATIVE CARE}

The United States needs to come up with more alternatives to family members and nursing homes for AD patient care. An example in The Netherlands is the tiny village of Hogewey, which includes tree-lined streets, shops, restaurants, a movie theater, a hairdresser, and 23 apartments carefully crafted to feel like home to the over 150 residents with AD. However, Hogewey is not a real village; it is a nursing home. The supermarket cashier, the restaurant manager, and the other village workers are all incognito nursing home staff, specially trained to care for people with dementia. Most of the residents think it is a real village (18).

The United States has AD facilities but nothing like Hogewey. Facilities such as AD villages serve several purposes: making the patients feel they are living a normal life, providing a safe environment, giving families peace of mind, and caring for patients in an environment different from the institutionalized atmosphere of a typical nursing home. Settings such as Hogewey have also been shown to reduce the need for medication and put patients more at ease and because they feel at home (18).

\section{RECOMMENDATIONS FOR PATIENTS AND CAREGIVERS}

\section{Prevention of AD}

Lifestyle modifications can help ward off AD (19). Such factors include maintaining a proper weight, blood pressure, blood glucose, and gut microbiome; getting daily exercise and sun exposure; socializing and engaging in mental activities; staying hydrated; avoiding aluminum, mercury, and toxic chemicals; and practicing whole-body detoxification.

Dietary modifications are also important (19). Foods should be low in unhealthful fats, high in fiber, high in antioxidants, organic, and not genetically modified. Healthful oils that can reduce the risk of $\mathrm{AD}$ include coconut oil, cold-pressed extra virgin olive oil, flaxseed oil, avocado oil, hempseed oil, and macadamia nut oil. Fruits particularly helpful in preventing AD are red grapes, cherries, strawberries, blueberries, raspberries, pomegranates, oranges, and plums. Particularly helpful vegetables are spinach, kale, broccoli, beets, Brussels sprouts, peppers, alfalfa sprouts, leafy greens, and eggplant. Consuming fresh cold-water fish high in omega- 3 fatty acids is beneficial, as is eating nuts high in vitamin $\mathrm{E}$ (almonds, pecans, and walnuts) and drinking herbal green tea. Sugar and wheat should be eliminated.

Finally, supplements such as vitamins $\mathrm{B}_{12}, \mathrm{C}, \mathrm{E}$, and $\mathrm{D}_{3}$, ginkgo biloba, magnesium, curcumin, resveratrol, silicon, acetyl-L-carnitine, docosahexaenoic acid, and a B-complex vitamin can help reduce the risk of $\mathrm{AD}$.

\section{Compassion}

It is important to remember what the patient is going through, as well as what the caregiver is going through. Love and compassion by all are key to allowing those living with AD to remain happy and healthy. This disease is not easy for anyone involved - the patient, the caregiver, or the family.

Figure 3 provides compassionate reminders from the perspective of the $\mathrm{AD}$ patient and from the perspective of the AD caregiver. Carefully reading these reminders and allowing the words to sink in will help inspire compassion in those who are currently traveling the AD journey or who may someday embark on that journey.

\section{CONCLUSION}

$\mathrm{AD}$ is a growing, devastating disease that affects not just the patient but the entire family, as well as putting a large cost burden on the entire U.S. health-care system. The disease is a tremendous source of stress to caregivers, not only financial stress but physical, emotional, time-related, work-related, and demographic stress. We need to find a cure for $\mathrm{AD}$, we need to increase education on its risk factors and on lifestyle modifications that may keep it at bay, and we need alternatives to the use of family members and nursing homes as care providers. But perhaps most important is that 
we need to remember love and compassion toward those who travel the AD journey.

\section{DISCLOSURE}

Barbara Grabher is an employee of Life Molecular Imaging and is the chief consultant and president of Grabher Consulting and Specialty Services. No other potential conflict of interest relevant to this article was reported.

\section{ACKNOWLEDGMENTS}

I thank Marybeth Farrell and Kathy Thomas for inviting me to contribute to the Journal of Nuclear Medicine Technology and Maria Costello for providing guidance for part of this article.

\section{REFERENCES}

1. Maurer K, Maurer U. Alzheimer: The Life of a Physician and Career of a Disease. New York, NY: Columbia University Press; 2003:1-22.

2. Dementia statistics. Alzheimer's Disease International website. https://www.alz. co.uk/research/statistics. Accessed September 12, 2018.

3. Alzheimer's Association. 2018 Alzheimer's disease facts and figures. Alzheimers Dement. 2018;14:367-429.

4. Alzheimer's Association. 2016 Alzheimer's disease facts and figures. Alzheimers Dement. 2016;12:459-509.

5. 2018 Alzheimer's disease facts and figures. Alzheimer's Association website. https://www.alz.org/media/Documents/alzheimers-facts-and-figures-infographic. pdf. Accessed September 12, 2018.

6. Das R. A silver tsunami invades the health of nations. Forbes website. https:// www.forbes.com/sites/reenitadas/2015/08/11/a-silver-tsunami-invades-the-healthof-nations/\#40f5a59b3efd. Published August 11, 2015. Accessed September 12, 2018.

7. Breitung JC. Forgetting: When to Worry, What to Do. Amherst, NY: Prometheus Books; 2008:82.

8. Blendon R, Benson J, Weldon K; Harvard School of Public Health. Five-country Alzheimer's disease survey. Alzheimer Europe website. https://www.alzheimer-
europe.org/content/download/21571/157322/file/Value of knowing-Powerpoint presentation of results.pdf. Published February 2011. Accessed September 12, 2018.

9. Ali N. Understanding Alzheimer's: An Introduction for Patients and Caregivers. Lanham, MD: Rowman and Littlefield Publishers, Inc.; 2012:50.

10. Early diagnosis: the value of knowing. Alzheimer's Association website. http:// act.alz.org/site/DocServer/Value_of_Knowing_Fact_Sheet_Public_Health_.pdf? docID=1781. Published April 2017. Accessed September 12, 2018.

11. Turkington C, Mitchell D. The A to Z of Alzheimer's Disease: A Concise Guide to Understanding and Coping with This Devastating Disease. New York, NY: Clearmark Books/Infobase Publishing, Inc.; 2010:248-253.

12. 2014 Alzheimer's Disease Facts and Figures: Use and Cost of Healthcare, Long-Term Care and Hospice. Vol. 10. Chicago, IL: Alzheimer's Association; 2014:42.

13. Long-term care providers and services users in the United States: data from the National Study of Long-Term Care Providers, 2013-2014. Centers for Disease Control and Prevention website. https://www.cdc.gov/nchs/data/series/sr_03/sr03_ 038.pdf. Published February 2016. Accessed September 12, 2018.

14. Hurd MD, Martorell P, Delavande A, Mullen KJ, Langa KM. Monetary costs of dementia in the United States. N Engl J Med. 2013;368:1326-1334.

15. Quote: Alzheimer's will bankrupt our system. Alzheimers.net website. https:// www.alzheimers.net/ronald-petersen-alzheimers-quote/. Published April 21, 2014. Accessed September 12, 2018.

16. Spencer PS. 5 biggest issues that sabotage family caregivers. Caring.com website. https://www.caring.com/articles/caregiver-issues. Accessed September 122018.

17. Mace N, Rabins P. The 36-Hour Day: A Family Guide to Caring for People Who Have Alzheimer's Disease, Related Dementias, and Memory Loss. 5th ed. Baltimore, MD: Johns Hopkins University Press; 2011:212-233.

18. Moisse K. Alzheimer's disease: Dutch village doubles as nursing home. ABC News website. http://abcnews.go.com/Health/AlzheimersCommunity/alzheimersdisease-dutch-village-dubbed-Truman-show-dementia/story?id=16103780. Published April 10, 2012. Accessed September 12, 2018.

19. Lanphier L. Reducing your risk for Alzheimer's disease. OAW Health website. http://oawhealth.com/2013/09/16/reducing-your-risk-for-alzheimers-disease/. Published September 16, 2013. Accessed September 12, 2018.

20. 10 requests from someone with Alzheimer's. Free Alzheimers Support website. http://www.free-alzheimers-support.com/wordpress/10-requests-from-someonewith-alzheimers/. Published January 2017. Accessed September 12, 2018.

21. Caregiver's 10 commandments. Understanding Dementia Facebook page. https:// www.facebook.com/UnderstandingDementia/photos/a.179042998937217/ 894872050687638/?type=3\&theater. Accessed September 12, 2018. 